\title{
'Absorptive link': an absorptive capacity and alliance approach to biotechnological product success
}

\author{
Desmond $\mathrm{Ng}$ \\ Dept. of agricultural economics, Texas A\&M University, 349B Blocker, 2124 TAMU, College Station, TX 77843-2124, USA; \\ dng@ag.tamu.edu
}

\begin{abstract}
As biotechnologies are increasingly specialized and interrelated, the research question posed by this study is: what determines a biotechnology firm's product performance, if the development and commercialization of drug products require multiple technologies that are not possessed by any one firm? In drawing on concepts from strategic alliance and absorptive capacity research, this study develops and empirically examines a concept of 'absorptive link' in the biotechnology industry. A firm's absorptive link underscores that a firm's ability to develop new products stems from its prior knowledge in commercializing new applications of resources held by not only the firm, but also that of its alliance partners. Such a concept generated 6 testable hypotheses to which were mostly supported in this study's Poisson regression analysis of the biotechnology industry. This study concludes by offering three key contributions to product performance research.
\end{abstract}

Keywords: Penrose resource based view, product innovation, prior knowledge

\section{Introduction}

A firm's competitive survival depends on its ability to successfully develop and bring products to the market (Deeds and Hill, 1996; Penrose, 1959; Schoonhoven et al., 1990). However, as technologies are increasingly specialized and interrelated (Bettis and Hitt, 1995), the creation of products often involves sourcing multiple technologies that are not held by any one firm (Pennings and Harianto, 1992; Powell et al., 1996; Rothaermel, 2001; Rothaermel and Deeds, 2004, 2006). For instance, in the biotechnology industry, the development of therapeutic drugs is the result of combining the research expertise of various biotechnology start-ups and the commercializing assets of large pharmaceutical companies (Baum et al., 2000; Pennings and Harianto, 1992; Pisano, 1990; Powell et al., 1996; Rothaermel and Deeds, 2004; Teece, 2000). Hence, given the interdependent nature of the biotechnology industry, the research question posed by this study is: what determines a biotechnology firm's product performance, if the development and commercialization of drug products require multiple technologies that are not possessed by any one firm?

As the development of products is inherently a process of novel resource recombinations (Danneels, 2002; $\mathrm{Ng}$, 2007; Pennings and Harianto, 1992; Penrose, 1959; Schumpeter, 1934), a firm's ability to absorb and integrate the resources or technologies of alliance partners is instrumental to a firm's product performance (e.g. Hess and Rothaermel, 2011; Rothaermel and Deeds, 2004, 2006; Rothaermel and Hess,
2007). Such an argument rests on the concept of 'absorptive capacity' (Cohen and Levinthal, 1990) which refers to a firm's 'ability to recognize the value of new information, assimilate it, and apply it to commercial ends' (128) [italics emphasized by this study]. In particular, since the development of a biotechnology firm's products requires transforming basic research technologies into commercialized products (Deeds and Hill, 1996; Nerkar and Roberts, 2004), such transformations often require assimilating the resources of its alliances partners. Thus, various studies have suggested that a biotechnology firm's absorptive capacity is a necessary requirement to reaping the benefits of alliances (Hoang and Rothaermel, 2005; Lane and Lubatkin, 1998; Mowery et al. 1996; Pennings and Harianto, 1992; Rothaermel and Hess, 2007).

Yet, although strategic alliance (Deeds and Hill, 1996; Rothaermel 2001; Rothaermel and Deeds, 2004) and absorptive capacity (Danneels, 2002; Helfat and Peteraf, 2003; Helfat and Raubitschek, 2001; Peteraf and Bergen, 2003) arguments have been used to explain a firm's product performance, most studies, however, fail to sufficiently integrate both perspectives (Rothaermel and Alexandre, 2009; Rothaermel and Hess, 2007). Prior research tends to identify firm or alliance level factors as primary explanations of product success, while mutually excluding the causal determinants of the other (Rothaermel and Hess, 2007). For instance, strategic alliance research (Chan et al. 1997; Deeds and Hill, 1996; Dyer and Singh, 1998; Powell et al., 1996; Rothaermel 2001; Rothaermel and Deeds, 2004) tends to understate a firm's ability to 'apply and commercialize' the 
resources of alliance members. While, absorptive capacity research tends to focus on organizational mechanisms that promote the application and commercialization of externally relevant information (see Lane et al., 2006; Jansen et al., 2005; Todorova and Durisin, 2007; Zahra and George, 2002), while providing limited consideration of the complementary and commercializing role of alliance partnerships.

As a result, there has been a growing but limited body of research that integrates these various levels of analysis (Lane et al., 2006; Lichtenthaler, 2009; Lichtenthaler and Lichtenthaler, 2010; Rothaermel and Hess, 2007; Zhao and Anand, 2009). For instance, in Rothaermel and Hess' (2007) study of the biotechnology industry, they argue and find that a firm's absorptive capacity is not only influenced by factors residing at the employee, firm and network levels of analysis, but can also be influenced by substitute and complementary relationships amongst these various levels. Yet, in spite of such contributions, such multi-level approaches (see also Rothaermel and Hess, 2007; Zhao and Anand, 2009) offer a limited attention to the nature of a firm's 'prior knowledge'. The nature of a firm's 'prior knowledge' is important to the concept of absorptive capacity because a firm's product performance not only depends on the firm's ability to assimilate externally relevant knowledge, but it also depends on a firm's 'prior knowledge' in 'applying' and 'commercializing' such external experiences (Cohen and Levinthal, 1990). Although there have been some efforts to examine such prior knowledge, the firm-alliance level studies of Zhao and Anand (2009), Rothaermel and Hess (2007) and Hess and Rothaermel (2011) and even that of absorptive capacity research (Jansen et al., 2005; Todorova and Durisin, 2007; Zahra and George, 2002) have focused their attention on the role of a firm's tacit knowledge (e.g. Rothaermel and Hess, 2007; Rothaermel and Deeds, 2006) or organizational mechanisms (Jansen et al., 2005; Todorova and Durisin, 2007; Zahra and George, 2002) in promoting the transfer of external knowledge, but not on the types of 'prior knowledge' that promote the 'application' and 'commercialization' of firm-alliance level experiences.

Hence, in order to address this research gap, a concept of 'absorptive link' is introduced to deal with this study's research question. Namely, to underscore the 'prior knowledge' (Cohen and Levinthal, 1990) aspects of the absorptive capacity concept, this study develops a concept of absorptive link. Such a concept is comprised of two categories of 'prior knowledge': a firm's functional and commercial knowledge of the various applications of resource use. Specifically, in explaining a firm's functional knowledge of resources uses, Penrose (1959) as well as more modern resource based approaches (Denrell et al., 2003; Ng, 2007) contend that the development of a firm's products stems from a firm's heterogeneous knowledge of the ways in which its resources can be applied to different productmarkets. Furthermore, a firm's prior knowledge not only entails a functional knowledge of a resource's varied uses, but also a commercial knowledge of their market viability. Such prior knowledge constitutes a firm's absorptive link to which serves to innovate new product-market opportunities by seeking new ways to apply and commercialize firmalliance level resources. Specifically, as the development of new products involves drawing on technologies or resources that are not held by any one firm, this study argues that a firm's product performance stems from its absorptive link to not only discover and commercialize its firm's resources' varied uses, but also that of its alliance partners.

To organize the development of this study, definitions used in this study are first stated. This is followed by a review of strategic alliance and absorptive capacity research. These areas are then integrated in which absorptive link arguments and hypotheses are developed and empirically tested in the biotechnology industry. Specifically, in drawing on a sample of 372 biotechnology firms in 2004, Poisson estimations examined the relationship between a biotechnology firm's absorptive link and alliances on its product performance. This study then concludes with its contributions and implications to product performance research.

\section{Conceptual model}

\section{Definitions}

As the biotechnology firm is the primary unit of analysis, the biotechnology firm is defined by a for profit firm that is involved in the research, development, and commercialization of human therapeutics (e.g. Hess and Rothaermel, 2011; Rothaermel and Deeds, 2004). This includes those biotechnology firms involved in the development of human therapeutic products, such as drug treatments for diabetes, cholesterol, cardiovascular diseases and other drugs for the prevention and improvement of human health. Human therapeutic products can also include diagnostic services and products. Hence, given this unit of analysis, a biotechnology firm's product performance is defined by the transformation of a firm's basic technological research into human therapeutic products and services of commercial value. Although there are various measures of product performance (Montoya-Weiss and Calantone, 1994), this definition is adopted because it is consistent with the 'applied' and 'commercializing' aspects of Cohen and Levinthals' (1990) concept of 'absorptive capacity' (see also Deeds and Hill, 1996; Nerkar and Roberts, 2004; Rothaermel 2001; Rothaermel and Deeds, 2004). Based on these definitions, strategic alliance explanations of product performance are discussed as follows: 


\section{Strategic alliances}

As the locus of product innovation increasingly depends on a network of technology and commercializing partnerships (e.g. Powell et al., 1996), the cooperation and pooling of alliance resources can complement a firm's competitive position (Baum et al., 2000; Chan et al., 1997; Deeds and Hill, 1996; Dyer and Singh, 1998; Harrison et al., 2001; Lichtenthaler, 2009; Lichtenthaler and Lichtenthaler, 2010; Powell et al., 1996; Rothaermel 2001; Rothaermel and Deeds, 2004; Rothaermel and Hess, 2007). As Chan et al. (1997) describe:

strategic alliances bring together otherwise independent firms to share resources in product design, production, marketing or distribution. Forging an alliance enable a firm to focus resources on its core skills and competencies while acquiring other components or capabilities it lacks from the market place (199)

Strategic alliances are important to the biotechnology industry because they provide access to external experiences that can transform a biotechnology firm's basic research inventions into commercialized innovations (Deeds and Hill, 1996; Nerkar and Roberts, 2004; Rothaermel and Deeds, 2004; Rothaermel and Hess, 2007; Schumpeter, 1934). For instance, strategic alliances amongst research start-ups serve to pool complementary research experience and thus promoting the creation of 'basic' research inventions (i.e. genome mapping and sequencing) that can exhibit various applications in the treatment of diseases (Baum et al., 2000; Liebeskind et al., 1996; McFadyen and Cannella, 2004; Powell et al., 1996). Yet, in order to bring such research inventions to the market, research start-ups tend to also form commercialization alliances to established pharmaceutical firms (Danzon et al., 2003; Graves and Langowitz, 1993; Rothaermel, 2001; Teece, 2000). Such commercializing alliances provide access to marketing, distribution and manufacturing assets that advance the development of basis research prototypes, such as drug candidates, into commercially viable innovations (Danzon et al., 2003; Graves and Langowitz, 1993; Rothaermel and Deeds, 2004; Teece, 2000). As these alliances complement a firm's competitive position, biotechnology studies (Deed and Hill, 1996, Rothaermel, 2001; Rothaermel and Deeds, 2004,2006 ) have found that a biotechnology firm's alliances positively influence its product performance.

Some alliance researchers however suggested that increasing strategic alliances could eventually yield diminishing returns to a biotechnology firm's product performance (Deeds and Hill, 1996; Rothaermel and Deeds, 2004, 2006). For instance, Deeds and Hill (1996) find that a biotechnology firm's product performance has a non-monotonic inverted U shape relationship to its strategic alliances. This diminishing effect arises because of basic cognitive limits in a firm's ability to manage multiple alliances (e.g. Deeds and Hill, 1996; Rothaermel and Deeds, 2004). To capture this positive yet diminishing effect of alliances, Hypothesis 1 constitutes our base hypothesis.

Hypothesis 1: a firm's product performance - number of products on the market - has an inverted U-shaped relationship to the total number of strategic alliances.

As alliances provide access to different types of resources (Shan et al., 1994), different types of alliances can yield different effects on a firm's innovation (Hoang and Rothaermel, 2005; Rothaermel and Deeds, 2006). For instance, strategic alliances can take a variety of exchange relationships involving licensing, manufacturing, research, marketing and development agreements (Chan et al., 1997; Harrison et al., 2001; Jones et al., 1997; Lane and Lubatkin, 1998; Osborn and Hagedoorn, 1997; Pennings and Harianto, 1992; Rothaermel and Deeds, 2004). Since research and marketing related resources are key requirements to a firm's product success (Dutta et al., 1999; Danneels, 2003), this suggests Research \& Development $(R \& D)$ and Marketing alliances should yield a greater influence on a firm's product performance than other types of alliances. The following is thus hypothesized:

Hypothesis 2: A firm's R\&D and marketing alliances have the greatest positive effect on a firm's product performance.

Moreover, in firm level studies of product performance, Dutta et al. (1999) and Danneels $(2002,2003)$ find research and marketing activities tend to mutually complement a firm's product performance. This is because research often requires efforts in marketing such that basic research technologies can be developed to meet the needs of a firm's customers (Dutta et al., 1999). Hence, in extending these arguments to R\&D and Marketing alliances, their mutual influences are also hypothesized:

Hypothesis 2a: A firm's product performance is positively related to the joint influence of a firm's $\mathrm{R} \& \mathrm{D}$ and marketing alliances.

\section{Absorptive link an integration of absorptive capacity and strategic alliances}

Yet, since innovation spans across multiple levels of analysis (Rothaermel and Hess, 2007; Lichtenthaler and 
Lichtenthaler, 2010), product innovation not only depends on a firm's ability to gain access to its partners' experiences, but it also depends on a firm's 'absorptive capacity' to assimilate such experiences. As a firm's absorptive capacity is directly a function of its 'prior knowledge' (Cohen and Levinthal, 1990; Danneels, 2002; Lane and Lubatkin, 1998; Mowery et al., 1996; Nerkar and Roberts, 2004; Pennings and Harianto, 1992), Cohen and Levinthal (1990) argue that increasing a firm's prior experiences increases a firm's memory to which increase a firm's ability to recall from its prior experience in assimilating and commercializing external information in the next period (e.g. Lane et al., 2006; Van den Bosch et al., 1999; Zahra and George, 2002;). Although a firm's memory - as a form of prior experience is central to this absorptive capacity concept (Cohen and Levinthal, 1990), behavioural and network explanations have argued excessive reliance on a firm's past memory or experiences can reduce a firm's ability to innovate. A reliance on past experiences can lead to routine behaviours that inhibit a firm's creativity and thus innovation (e.g. Jansen et al., 2005; Levinthal and March, 1993; Nelson and Winter, 1982). Furthermore, network studies find that a firm's reliance on past experiences will favour partners with similar experiences and thus the selection of redundant alliance partners will inhibit a firm's efforts to innovate (e.g. Coleman, 1988; Ng, 2004; Ng et al., 2006).

\section{Concept of absorptive link}

As the concept of absorptive capacity exhibits multidimensional properties (e.g. Jansen et al., 2005; Lichtenthaler, 2009; Lichtenthaler and Lichtenthaler, 2010; Todorova and Durisin, 2007; Zahra and George, 2002), this study however argues that a firm's absorptive capacity can be driven by other types of 'prior knowledge'. As the development of products stems from a firm's resources (e.g. Denrell et al., 2003; Penrose, 1959; Ng, 2007), this study argues that a firm's prior knowledge entails more than a firm's memory but can also entail a knowledge about the functional and commercial uses of firm-alliance level resources. Such knowledge serves to not only discover new ways to apply firm and inter-firm level resources to new product-markets, but also to realizing their commercial potential. This study argues that this prior knowledge constitutes a firm's absorptive link. Specifically, a firm's absorptive link is defined by a firm's ability to draw on its prior knowledge of the functional uses of its resources for the discovery and commercialization of new product-market opportunities found inside and outside of its organizational boundaries.

\section{Absorptive link: knowledge of the functional use of resources}

To elaborate on the functional aspects of this absorptive link concept, a firm's knowledge of its resources' functional uses originates from Penrose's (1959) and later Wernefelt's (1984) notion of 'resource duality'. 'Resource duality' refers to the idea that a firm's resources and products are 'two sides of the same coin' (Wernerfelt, 1984). Resources duality underscores that the same set of resources can be applied to different market settings (Penrose, 1959). Hence, unlike Barney's (1986) resource based view, resources are heterogeneous not because they have unique physical attributes, but rather resources are heterogeneous in their functional uses (Penrose, 1959). As Penrose (1959) describes:

the fact that most resources can provide a variety of different services is of great importance for the productive opportunity of a firm. It is the heterogeneity, and not the homogeneity of the product services available or potentially available from its resources that give its unique character (75).

This resource duality is also expressed by Teece (1982) in which he notes,

... the final products produced by a firm at any given time merely represent one of several ways in which the organization could be using its internal resources (Penrose, 1959) ... a firm's capabilities lie upstream from the end product - it lies in a generalizable capability which might well find a variety of final product applications (p. 45).

In particular, as product innovation is inherently a process of novel resource combinations (Danneels, 2002; Pennings and Harianto, 1992; Schumpeter, 1934), the dual nature of resources is central to a firm's product innovation process. This is because a firm's prior knowledge of resource uses provides 'cues' in the selection of other resources. This yields the discovery of other resources that can reveal an 'eventual combination' of resources whose functional uses can propel the development of new product innovations (Denrell et al., 2003; Ng, 2007). As Denrell et al., (2003) describe,

... when many of the necessary components were available to the firm, it is possible that the value of the eventual combination could be foreseen. The process is analogous to an individual facing a jigsaw puzzle with only a few lacking piece (987). 


\section{Functional knowledge of resources uses: cumulative knowledge}

This ability to see this 'eventual combination' stems from a firm's cumulative knowledge of functional resource uses. A firm's 'cumulative' knowledge of resource uses is argued to positively influence a firm's absorptive link in discovering new product opportunities. This is because a firm with greater cumulative experiences develops a greater understanding of the functional uses of the 'component parts' of a firm's resource bundle. By understanding the functional uses of each component part, this cumulative knowledge enables the firm to see how these resources fit with others resources. This facilitates the discovery of new resource combinations and uses. Hence, since the concept of absorptive link is driven by a firm's prior knowledge of the functional uses of its resources, a firm's absorptive link in discovering new products is influenced by those firms who possess greater cumulative experiences because such experiences enable the firm to see an 'eventual combination' of resources and uses that is required in the product innovation process. The following is hypothesized:

Hypothesis 3: A firm's accumulated experiences are positively related to its product performance.

\section{Moderating effects of alliances on a firm's cumulative knowledge}

However, unlike Penrose (1959) who focuses on firm level explanations of the product discovery process (e.g. Denrell et al., 2003; Ng, 2007), the concept of absorptive link extends a firm's discovery of resources uses beyond its organizational boundaries. By drawing on a firm's cumulative knowledge, a firm's absorptive link reflects an ability to not only see an 'eventual combination' of resources that are held within the firm, but also to see how such a combination fits within a greater 'puzzle' of resources held by its alliance partners. That is, by leveraging a firm's cumulative knowledge of resource uses, it enables the firm to infer the resource combinations and uses of its alliance partners. This is consistent with empirical studies that find as firms accumulate experiences in the development of new technologies, a firm increases its ability to determine the compatibility of externally relevant technologies (Hoang and Rothaermel, 2005; Pennings and Harianto, 1992).

Although this concept of absorptive link leverages the resource uses of a firm's alliance partners, a firm's absorptive link is nevertheless subject to diminishing effects in its alliances. Namely, as a firm leverages its cumulative knowledge to discovering new ways to combine its resource uses with that of its alliance partners, a firm's cumulative knowledge can be subject to 'network myopic' (Coleman, 1988) effects. This is because as a firm continues to leverage its cumulative knowledge of resource uses, this prior knowledge constrains the firm to exchange with only those alliance members that share similar prior experiences. This is supported by network closure arguments whereby firms tend to develop relationships with those who share similar beliefs and experiences (Coleman, 1988; Gargiulo and Benassi, 2000; Hoang and Rothaermel, 2005; Ng, 2004). Such a closed network generates a 'network myopia' that stifles a firm's absorptive link to discovering new resource combinations and uses and thus reducing the product performance benefits of a firm's alliances. This positive yet diminishing effect on a firm's absorptive link is thus captured by the following:

Hypothesis $3 a$ : The effect of a firm's accumulated experiences on product performance is positively moderated by the diminishing effects of a firm's alliances.

\section{Functional knowledge of resources uses: Diverse knowledge}

In addition to a firm's cumulative knowledge, a firm's diverse knowledge of resource uses constitute another functional aspect of a firm's absorptive link. According to absorptive capacity research, diversity in a firm's prior knowledge strengthens a firm's ability to assimilate external information and promotes the development of new innovations (Cohen and Levinthal, 1990; Nerkar and Roberts, 2004; Pennings and Harianto, 1992; Zahra and George, 2002). As Cohen and Levinthal (1990) describe:

a diverse background [knowledge] provides a more robust basis for learning because it increases the prospect that incoming information will relate to what is known (131).

Yet, since resources have heterogeneous uses (Penrose, 1959), a Penrosian explanation, argues that diversity in a firm's knowledge extends beyond the relational arguments of Cohen and Levinthal (1990). Specifically, a firm's diverse knowledge of resource uses capitalizes on the 'heterogeneous in use' (Penrose, 1959) aspects of resources in which such diversity not only enables the firm to see a greater variety of applications or uses from any given set of resources, but as a result enables the firm to see a 'larger' puzzle of resource combinations and uses than that of a firm's cumulative experiences. Hence, a firm's ability to develop new products arises not just because a firm's diversity of experiences promotes an ability to relate to a broader set of external experiences (Cohen and Levinthal, 1990), but it 
can also arise because a firm's diversity in their knowledge of resource uses enables the firm to see a 'larger' combination of resources and uses (e.g. Ng, 2007; Penrose, 1959). Such a diverse knowledge of resource uses is thereby argued to positively impact a firm's absorptive link in introducing new products to the market. The following is thus hypothesized:

Hypothesis 4: A firm's prior knowledge diversity is positively related to its product performance.

\section{Moderating effects of research alliances on a firm's diverse knowledge}

With a firm's diverse knowledge of resources uses, a firm's absorptive link enables the firm to develop products by assimilating the resource uses of its research alliances. This diverse knowledge of resources uses can be manifested by a biotechnology firm's diversity of research programs (see also Rothaermel and Deeds, 2006). Biotechnology firms involved in a diversity of research programs, such as cancer therapies, protein engineering, medical diagnostics, screening for molecular compounds are more likely to understand the medical applications of such basic research and thus are better able to relate and recombine the basic research of its alliance partners. Namely, the ability to relate a firm's prior experiences to the experiences of alliance members requires that the firm has some overlapping knowledge experiences with its alliance partners (Lane and Lubatkin, 1998; Mowery et al., 1996). For instance, according to Lane and Lubatkin (1998), they show that the transfer of inter-firm knowledge is dependent on a firm having some prior knowledge that is basic or fundamental to the new and external knowledge. Basic knowledge consists of the 'general understanding of the traditions and techniques upon which a discipline is based' (Lane and Lubatkin, 1998: 464). Hence, in building on Lane and Lubatkins' (1998) arguments, the greater the diversity of research programs, the greater is the likelihood that the firm possesses knowledge that is basic or fundamental to its aligning partners. This diversity of research programs not only promotes a greater understanding of the basic 'disciplinary knowledge' of its alliances, but it also enables the firm to better understand their combined uses in the development of drug candidates.

Although a firm's diversity of research experiences positively influences a firm's absorptive link in leveraging the research uses of its alliance partners, this firm's absorptive link is, however, subject to diminishing return in its research alliances. This is because even though a firm's diversity increases a firm's absorptive link to recognize a broader combination of resource uses from its research partners, this diversity renders the firm increasingly vulnerable to assimilating incompatible research that erodes a firm's core area of research expertise. Excessive dependence on research alliances will eventually reduce the product performance benefits of a firm's absorptive link and is as hypothesized as follows:

Hypothesis 4a: The effect of a firm's prior knowledge diversity on product performance is positively moderated by the diminishing effects of its research alliances.

\section{Absorptive link: commercial knowledge of resource use. products in development}

Since the development of products also requires that a firm be able to commercialize the varied functional uses of resources, the concept of absorptive link thereby not only includes a firm's cumulative and diverse knowledge of resource uses, but also includes knowledge surrounding their commercial potential. A firm's products in development (Nichols-Nixon and Woo, 2003) constitutes one such aspect of this commercial knowledge. Namely, in order to commercialize basic research, a firm's knowledge of resource uses needs to be imbued into a prototype product, such as a drug candidate. Such a prototype drug candidate is involved in a product development and regulatory phase involving clinical trials and is subjected to FDA regulation (e.g. Rothaermel and Deeds, 2004). Yet, since only 5\% of all drug candidates make it to the clinical trials of the product development phase (Graves and Langowitz, 1993), a firm's products in development thereby signify knowledge surrounding its commercial viability and potential prospects for market acceptance (e.g. Rothaermel and Deeds, 2004). As a result and consistent with Nicholls-Nixon and Woo (2003), a firm's commercial knowledge is characterized by a firm's products in development in which such knowledge underscores that the innovation of new products not only arises from an understanding of the varied uses of a firm's resources (i.e. basic research involved in developing a drug candidate), but also knowledge of their commercial potential (i.e. commercializing experiences in moving the drug candidate through market approval). To capture this commercializing aspect of the absorptive link concept, the following is hypothesized:

Hypothesis 5: A firm's products in development are positively related to its product performance. 


\section{Moderating effects of commercial alliances on a firm's product in development}

A firm's products in development also enable the firm's absorptive link to commercialize the resources uses of its alliance partners. As a firm's products in development signify a commercial readiness or a 'proof of concept', it generates opportunities to collaborate with firms that possess the requisite commercializing skills and resources (Rothaermel and Deeds, 2004). This, as a result, generates alliance opportunities in manufacturing, marketing, distribution and other commercializing related alliances (Rothaermel and Deeds, 2004). However, a firm's absorptive link is subject to the diminishing effects of commercializing alliances. This is because since a firm's products in development demonstrate significant potential for commercial success, this invites opportunistic rent seeking behaviours amongst its commercial alliance partners. Such rent seeking behaviour exposes the firm to opportunistic threats of adverse selection, moral hazard and hold up (Jones et al., 1997; Osborn and Hagedoorn, 1997: Pisano, 1990). Hence, even though a firm's products in development serve to attract commercial partnerships, the greater the number of such commercial alliances, the greater is the potential for the firm to be subject to these various forms of opportunism. This reduces a firm's absorptive link in commercializing the resource uses of its commercial alliance partners. This is captured by the following absorptive link hypothesis:

Hypothesis $5 a$ : The effect of a firm's product in development on product performance is positively moderated by the diminishing effects of a firm's commercializing alliances.

\section{Commercial knowledge of resource use: mergers and acquisitions (M\&A)}

The commercializing aspects of a firm's absorptive link are also influenced by a firm's knowledge or history of M\&A experiences. As the biotechnology has experienced a long history of M\&A activity, such M\&A are commonly motivated by scale efficiencies and revenue based synergies (Capron, 1999; Graves and Langowitz, 1993; Walter and Barney, 1990). A firm's knowledge or history of M\&A thereby reflects a firm's competency in exploiting scale efficient practices and in exploiting product synergies. As these competencies are experientially based and are mutually related to the commercialization of products, a firm's M\&A experiences should thereby positively impact a firm's ability to 'see' the commercial applications or uses from its resources. Hence, in addition to a firm's products in development, a firm's knowledge or history of M\&A reflects another 'commercialization' aspect of the absorptive link concept and is hypothesized as follows:

Hypothesis 6: A firm's history of mergers and acquisitions has positive effect on a firm's product performance.

\section{Moderating effects of research alliances on a firm's M\&A}

A firm's history of M\&A also enables the firm's absorptive link to exploit the benefits of its research alliances. In the biotechnology industry, M\&A are motivated by excess capacity arguments (Danzon et al., 2003). Excess capacity occurs when a firm faces gaps or shortages in their pipeline of drugs to which render a firm's current level of specialized manufacturing, sales and marketing capital excessive (Danzon et al., 2003). Such problems of excess capacity arise because there is often competition among established pharmaceutical firms for research projects (Danzon et al., 2003; Pisano, 1990; Rothaermel and Deeds, 2004; Teece, 2000). Such competition can dry up a firm's drug pipeline and thus renders a firm from fully utilizing its M\&A experiences. With this threat of excess capacity, a biotechnology firm is induced to seek research alliances to fill up their drug pipeline so as to more fully utilize this commercializing experience. This is consistent with Penrose's (1959) who argues that a firm's growth is motivated by inducements to improve the utilization of slack or unused capital (e.g. Ng, 2007). As a result, with a firm's history of M\&A, this suggests that a firm's absorptive link seeks to form research alliances because by gaining access to research, it more fully utilizes a firm's commercial experiences in bringing basic research to the market.

However, unlike the diminishing effects of prior hypotheses, the moderating influence of a firm's research alliance on its absorptive link is not subject to a diminishing return effect. Due to the scarcity and thus competition of research projects (Danzon et al., 2003; Graves and Langowitz, 1993; Pisano, 1990), the selection of research projects is subject to a 'pecking order' effect (see also Rothaermel and Deeds, 2006). Due to the threat of excess capacity, a firm is induced to seek the most promising and commercializable research projects first. Subsequent research alliance partnerships then lead to eventual reductions in firm performance because competition for the most promising research projects leaves fewer remaining projects with commercial potential. Hence, this pecking order effect suggests that there is a first mover advantage in seeking research alliances. Yet, since biotechnology research continues in a rapid and at a times at a revolutionary technological pace (Liebeskind et al., 1996; Pisano, 1990), new and promising research discoveries are continually being injected with in the biotechnology 
technology landscape. This suggests that further increases in research alliances can provide a firm access to the most current and potentially promising research. To capture this non-monotonic $U$ shape effect, the moderating effects to a firm's absorptive link is hypothesized as follows:

Hypothesis 6a: The effect of a firm's history of M\&A on product performance is moderated by a $U$ shape relationship to a firm's research alliances

\section{Method}

\section{Data and sample}

In using one of the most commonly used databases in the biotechnology industry (Deeds and Hill, 1996; Lane and Lubatkin, 1998; Powell et al., 1996; Rothaermel, 2001; Rothaermel and Deeds, 2004, 2006; Hess and Rothaermel, 2011), this study draws from the 'BioScan' database to empirically examine the six absorptive link hypotheses. This study's empirical analysis is based on the 2004 edition of BioScan in which a sample of 372 public biotechnology and pharmaceutical companies is used. Consistent with samples used in prior studies (see Deeds and Hill, 1996; Hoang and Rothaermel, 2005; Rothaermel, 2001; Rothaermel and Deeds, 2004, 2006), this sample contains firms that produce human therapeutic products and related diagnostic services and products. However, unlike prior studies, this study's sample is based on a more recent sampling period of 2004 . For instance, Rothaermel and Deeds' (2006) study period was based in 1997 and more recently, Hess and Rothaermels' (2011) study was based on a 1997-2003 sampling period. To our knowledge, this study's sample reflects one of the most up to date samples in studies of product performance in the biotechnology industry.

\section{Measures}

\section{Dependent variable}

As the dependent variable is a firm's product performance, the aggregate number of commercialized firm products is measured by a count variable (see also Rothaermel and Deed, 2006), Products. Commercialized products are products that have completed all phases of product development - preclinical, phase I, phase II and phase III, received FDA approval - and are currently on the market. This definition is consistent with one of the absorptive capacity (output) measures (i.e. new product announcements) proposed by Zahra and George (2002). Similar definitions of firm performance have also been used in prior product studies (Deeds and Hill, 1996; Nerkar and
Roberts, 2004; Rothaermel 2001; Rothaermel and Deeds, 2004, 2006;).

\section{Independent variables}

Strategic alliances: A biotechnology firm's strategic alliances, Alliance, is a count variable of the cumulative alliances formed by the firm, since founding ${ }^{1}$. This strategic alliance variable, Alliance, consists of the aggregation of Licensing, Research and Development (R\&D), Marketing, Manufacturing, and Distribution, agreements (see also Chan et al., 1997; Deeds and Hill, 1996; Lane and Lubatkin, 1998; Powell et al., 1996; Rothaermel and Deeds, 2004, 2006). To examine Hypotheses 2a and 4a, R\&D and Marketing agreements were used to construct the respective $R \& D$ and Marketing alliances. Furthermore, to examine Hypothesis $5 a$, a commercial alliance (C.Alliance) variable was also created by aggregating Licensing, Marketing, Manufacturing and Distribution agreements. To test for the non-monotonic influences of strategic alliances, the quadratic form of these variables were constructed.

A firm's absorptive link as prior knowledge: Since a firm's absorptive link is driven by its prior knowledge, a firm's absorptive link is proxied by four knowledge measures. First, a firm's age, Age, is used as a broad proxy to capture a firm's prior cumulative knowledge of resource uses. Although this is a course grained measure, other types of cumulative knowledge, such as learning curve effects, were controlled for by a firm's size with the variable, Employees (see also Rothaermel and Deeds, 2006). To capture a firm's diverse knowledge of resource uses, a firm's research diversity, Diversity, is used (see also Rothaermel and Deeds, 2006). Diversity is a count of the distinct number of technological and/or research areas of specialization. This diversity measure reflects the number of subfields in which the firm has participated in. This diversity measure has also been used by Rothaermel and Deeds (2006) and Shan et al. (1994). To capture the commercializing aspects of the absorptive link concept, a firm's commercial knowledge is measured by its cumulative number of products in development (see also Nicholls-Nixon and Woo, 2003; Rothaermel and Deeds, 2004). A firm's products in development, P.Dev., is a count variable of all products that have entered clinical trials but have not yet reached the market. The other commercializing aspect of the absorptive link concept is captured by a firm's history of mergers and acquisitions. $M \& A$ are used to capture a firm's experiences from the acquisition or loss of knowledge through $M \& A$ activities. It is computed as

\footnotetext{
${ }^{1}$ For some of the firms in this sample, they have alliances that trace back to 1980 (see also Rothaermel and Deeds, 2004).
} 
the difference in the cumulative number of firm mergers less divestitures, $M \& A$, since the firm's founding (see also Rothaermel and Deeds, 2006). The moderating impacts of alliances on a firm's absorptive link are measured by the interactions between each of these four measures of prior knowledge with each of their respective alliances.

Control variables: In knowledge intensive industries, firm size is measured by the number of employees, Size (Graves and Langowitz, 1993; Pennings and Harianto, 1992; Rothaermel and Deeds, 2004; Shan et al., 1994). Moreover, to account for institutional differences, the location of the firm, Location, is coded as a dummy variable (0 US based, 1 non-US based) (Rothaermel and Deeds, 2004, 2006). The number of subsidiaries, Subsidiaries, held by a firm is included because they provide access to foreign markets and/or provide entrance into new product-markets (Rothaermel and Deeds, 2006). Lastly, the number of institutional investors, Investors, (i.e. investors from major banks, fund agencies) is also included because investors provide sources of funding necessary to bring products to markets (Rothaermel and Deeds, 2004).

\section{Estimation procedure}

Poisson and Negative binomial estimations are often used (Wooldridge, 2003) when the dependent variable of interest involves count data (see also Rothaermel and Deeds, 2006; Rothaermel and Hess, 2007; Hess and Rothaermel, 2011; Wooldridge, 2003). This is because as count data does not have a normal distribution other estimation procedures, such as OLS, would result in biased and inefficient estimates (Wooldridge, 2003). In this study, Poisson regression using Maximum Likelihood Estimation (MLE) methods was chosen not only because the dependent variable, Products, is a count variable, but also because $34.5 \%$ of this sample exhibits zero observations. According to Greene (2000) and Wooldridge (2003), the Poisson estimation procedure is generally appropriate when a significant population of the sample contains zero values. However, one of the assumptions of a Poisson regression is it requires that the mean is equivalent to its variance. Negative binomial regressions have thereby been proposed to relax such a restriction (see Rothaermel and Deeds, 2004). Yet, a uni-variate parametric estimation of the dependent variable does not support this probability distribution (Simetar Software) and therefore the Poisson regression is used in favour of the Negative binomial model (see also Rothaermel and Deeds, 2006). Wooldridge (2003) also argues the Poisson regression is robust to the restriction of mean-variance equivalence. Hence to test hypotheses 1-6, MLE estimations of a Poisson regression was applied to eight models. Models corresponding to each of the tested hypotheses were estimated with the Shazam econometrics software (version 9.0).

When estimating these models, a number of distinctions should, however, be noted. First, as a firm's absorptive link is moderated by its alliances, such moderating effects are tested through interactions between a firm's prior knowledge and that of its alliances. These interactions are standardized (Aiken and West, 1991). This is because since the concept of absorptive link is mutually related to a firm's alliances, these variables are likely to be strongly correlated. Hence, the standardization of these interacting variables was done to overcome problems of multi-collinearity (Aiken and West, 1991; see also Rothaermel and Deeds, 2006). To standardize these variables, the absorptive link and alliance variables are 'mean centered' the estimation (Aiken and West, 1991; see also Rothaermel and Deeds, 2006). Lastly, as there was considerable variability in the size variable, Employees, has been log transformed to minimize heteroscedastic influences (Wooldridge, 2003).

\section{Results}

The descriptive statistics for the theoretical variables of interests and their correlations are shown in Table 1 and the Poisson regression estimates are shown in Table 2. Given the interrelationships between the concept of absorptive link and alliances - as well as other variables -, the models in Table 2 were assessed for multi-collinearity. To measure multi-collinearity, the condition index or variance inflation factor for each of the models was calculated. Multicollinearity is moderate to strong when the condition index falls within a range of 10 to 30 (Gujarati, 1988). Because the variables of theoretical variables of interest were standardized, most of the models - with the exception of models Hypothesis $2 \mathrm{a}$ and $4 \mathrm{a}$ - were below the 10 point cut off. For instance, all models with the exception of models Hypothesis $2 \mathrm{a}$ (condition index $=14.45$ ) and $4 \mathrm{a}$ (condition index $=13.08)^{2}$ did not exceed 9.98. For these remaining models, problems of multi-collinearity should be taken into account when interpreting their estimated coefficients.

\footnotetext{
${ }^{2}$ For these remaining models, a common procedure for the correction of multi-collinearity is to combine correlated variables into a single variable. However, as one can see in Hypothesis 4a., the aggregation of $R \& D$, Licensing, Marketing, Distribution and Manufacturing into a single Alliance variable, the Variation Inflation factor for model 5 dropped from 14.45 (model 3) to 13.08. Hence, in spite of such corrective procedures - in addition to that of standardization, these model estimates need to take problems of multi-collinearity into account when interpreting these model estimates.
} 


$$
\begin{aligned}
& \text { Diversity } \\
& M \& A
\end{aligned}
$$

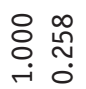

$$
\begin{aligned}
& \text { Alliances }
\end{aligned}
$$

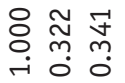

$$
\begin{aligned}
& \text { Manufacturing }
\end{aligned}
$$

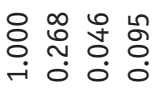

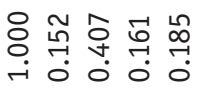

$$
\begin{aligned}
& \text { Distribution } \\
& \text { Marketing } \\
& \text { Licensing } \\
& R \& D \\
& \text { 윰 }
\end{aligned}
$$

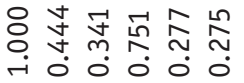

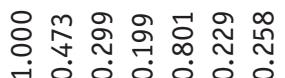

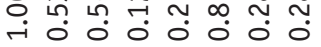

$$
\begin{aligned}
& \text { Size }
\end{aligned}
$$

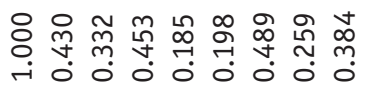

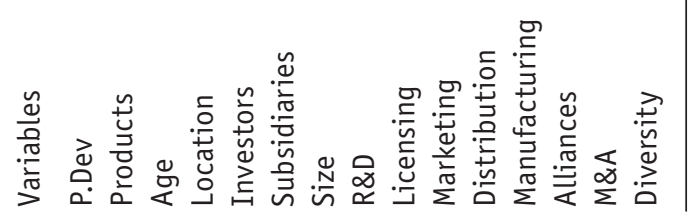




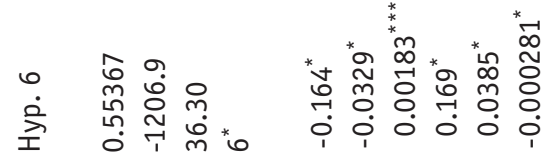

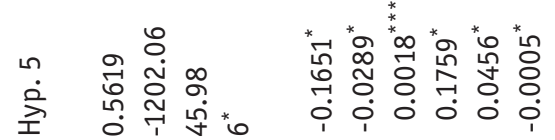

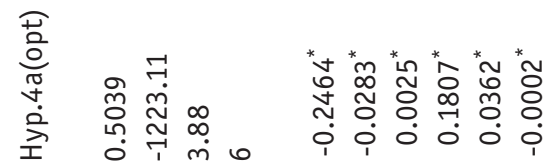

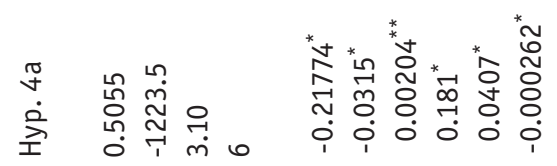

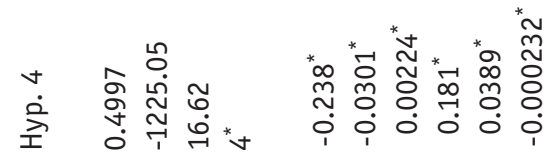

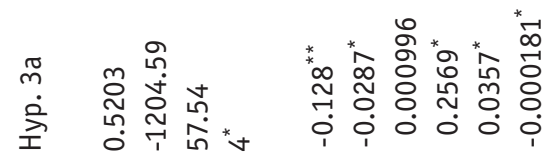

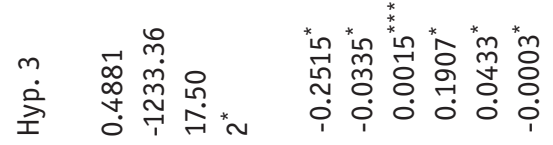

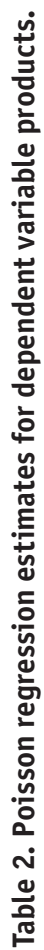

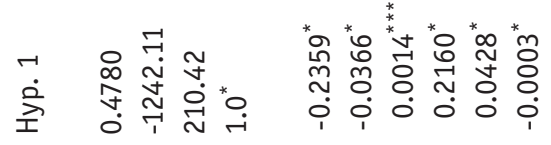

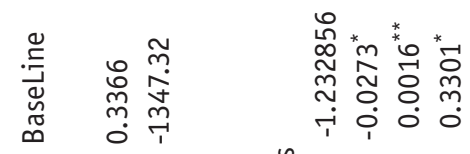

岀 $\times$ 节

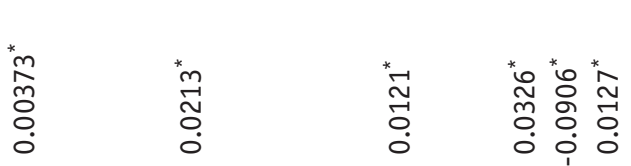

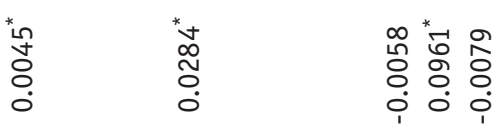

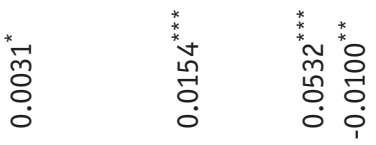

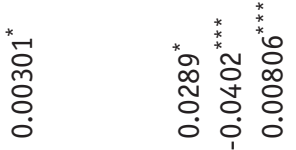

ֻั0

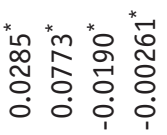

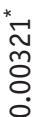

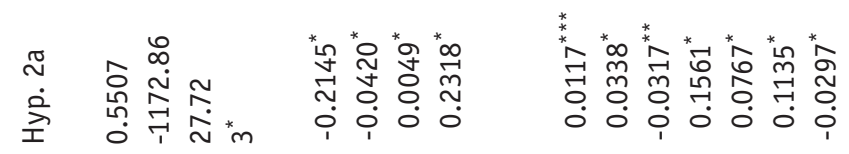

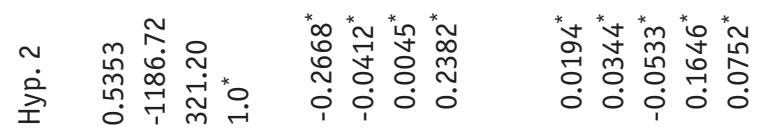

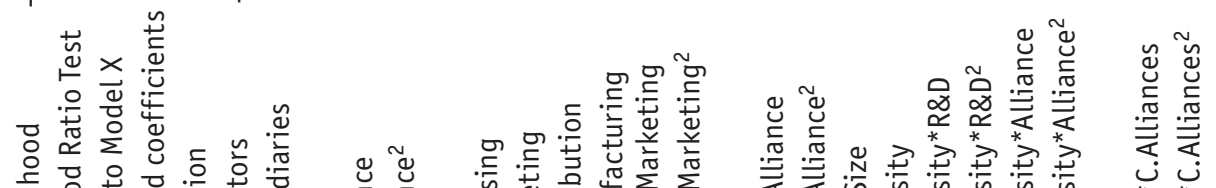

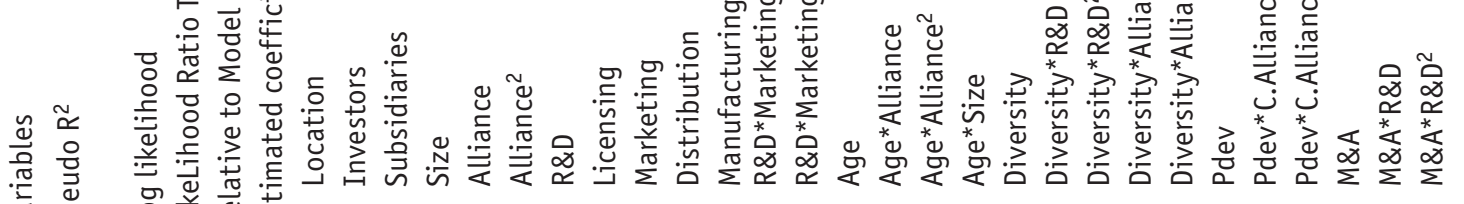


According to Table 2, the base line model indicates that all control variables with the exception of Location were significant. The subsidiary (Rothaermel and Deeds, 2004) and size (Rothaermel and Deeds, 2006) coefficients are significant at their respective 5\% and 1\% levels and are consistent with prior expectations. The investor coefficient was significant at the $1 \%$ level but was negative. This negative estimate may be due to the fact that the count nature of the investor variable does not account for the magnitude of investments. With regards to the main variables of interest, model Hypothesis 1 - as well as in all remaining models - show that the Alliance and Alliance 2 estimates are significant and exhibit an inverted $U$ shape relationship to a firm's product performance. Hypothesis 1 is supported. In model Hypothesis 2 and with the exception of Marketing alliances, all alliances - R\&D, Licensing, Distribution and Manufacturing alliances - were significant $(P<1 \%)$ and positive. Increasing a firm's R\&D, Licensing, Distribution and Manufacturing alliances by 0.1 or $10 \%$ yield a respective increase of $0.194 \%, 0.344 \%, 1.64 \%$, and $0.752 \%$ to a firm's number of products. As $R \& D$ has the lowest impact to a firm's product performance and given that the Marketing alliance coefficient was negative and significant $(P<1 \%)$, Hypothesis 2 is not supported. However, as shown in model Hypothesis $2 \mathrm{a}$, the interaction coefficient between the $R \& D$ and Marketing alliances is positive and significant $(P<1 \%)$ and thus providing support for Hypothesis 2a. Although this result confirms Hypothesis 2a, the product-marketing literature also indicates that an excessive focus on customer marketing can crowd out a firm's efforts to innovate (e.g. Christensen and Bower, 1996; Danneels, 2003; Hamel and Prahalad, 1991). Hence, to examine this effect, we also included a squared Marketing alliance term to this model. As the interaction between $R \& D$ and Marketing ${ }^{2}$ alliance is negative and significant $(P<1 \%)$, the complementary effect described in Hypothesis 2a appears to diminish with increasing Marketing alliances. This lends support to the 'tyranny of the served market' argument made by productmarketing researchers (e.g. Christensen and Bower, 1996; Danneels, 2003; Hamel and Prahalad, 1991).

To examine the absorptive link arguments, model Hypothesis 3 - as well as in models $4 a-6^{3}-$ shows a firm's age is positive and significant $(P<1 \%)$ and thus supporting Hypothesis 3. Model Hypothesis 3a introduces the interaction between a firm's age and its alliances. Yet, since both a firm's age and size can be potentially

\footnotetext{
${ }^{3}$ To be consistent with model Hypothesis 3 that only examined the cumulative aspects of the absorptive link variable, model Hypothesis 4 was used to examine the exclusive effects of a firm's diversity of knowledge resource on its product performance. Both variables are however then included in the subsequent model.
}

correlated, these firm level interactions were controlled for when assessing this absorptive link hypothesis. This is because since size is measured by the number of a firm's employees, each employee possesses understanding of the functional uses of its firm's resources. Therefore, a firm with a large number of employees may also possess great knowledge of resource uses and thus can interact with a firm's cumulative experiences, age. Therefore to control for such influences, their interactions are also included in the model Hypothesis 3a. When controlling for this firm level interaction, the absorptive link between a firm's age and alliances shows that their interaction coefficient is positive and significant $(P<1 \%)$. The diminishing effect of alliances on a firm's age is negative and significant $(P<1 \%)$. These results support Hypothesis $3 a$.

In model Hypothesis 4 as well as in all remaining models, a firm's diversity estimate is positive and significant $(P<1 \%)$. Hypothesis 4 is supported. However, with respect to the moderating effects of $R \& D$ on a firm's absorptive link, the Diversity $^{*} R \& D$ interaction has a negative estimate that is significant $(P<1 \%)$. While, the Diversity ${ }^{*} R \& D^{2}$ interaction has a positive estimate that is significant $(P<10 \%)$. As Hypothesis 4 a predicts a respective positive and negative estimate, these findings do not support Hypothesis 4a. Moreover, in model Hypothesis 5, the products in development, P.Dev., estimate was not significant and thus Hypothesis 5 was not supported. With respect to the moderating influences on a firm's absorptive link, the P.Dev. ${ }^{*}$ C.Alliances interaction is positive and significant $(P<1 \%)$. However, this absorptive link did not exhibit any significant diminishing effects and therefore only the positive moderating effects of Hypothesis 5a was supported. In examining model Hypothesis 6, a firm's history of M\&A is positive and significant $(P<1 \%)$. Hypothesis 6 is supported. With respect to the moderating effects to a firm's absorptive link, the interaction estimates of a firm's M\&A and Research Alliances are all significant $(P<1 \%)$ and have the predicted signs described in Hypothesis 6 a.

\section{Discussion}

In relating our empirical findings to broader research on product innovation, the support for Hypothesis 1 in model Hypothesis 1 confirms earlier findings that indicate a biotechnology firm's product performance is a nonmonotonic function of its alliances (Rothaermel and Deeds, 2004, 2006; Hess and Rothaermel, 2011). However, unlike these earlier studies, this study's findings are based on a later sampling period to which suggests that this nonmonotonic relationship may be robust to different periods of industry development. Furthermore, as alliances have been previously reported (Rothaermel and Deeds, 2006) 
and/or argued (Hess and Rothaermel, 2011; McEvily and Chakravarthy, 2002) to have differential effects on a firm's product performance, model Hypothesis 2 adds to this discussion. Model Hypothesis 2 shows that different alliances yield different effects on a biotechnology firm's product performance. Although we did not find support for Hypothesis 2, one possible explanation for this lack of support is that given the long lagged times in the drug development process (e.g. Powell et al., 1996), R\&D alliances may have a latent effect on a firm's product performance that is not captured by the cross sectional nature of this model. Moreover, with respect to a firm's marketing alliance, an increase of 0.1 or $10 \%$ in the number of marketing alliances yielded a decrease of $0.533 \%$ in the firm's product performance. Although unexpected, this finding appears to be consistent with the withdrawal of marketing activities among major pharmaceutical firms. For instance, Bristol Meyers had announced its withdrawing of conventional TV advertising and Weyer has announced significant reductions in its sales forces. Such reductions in marketing activities have been attributed to the increasing consumer distrust of drug advertisements (Forbes, 2005). Our negative coefficient findings may be attributed to some of these considerations. Although Hypothesis 2 was not supported, model Hypothesis 3a nevertheless did find support for the complementary effect between $R \& D$ and marketing alliances on a firm's product performance. This finding builds on Rothaermel and Hess (2007) study in which they found a biotechnology's R\&D capability exhibited a complementary effect to its biotechnology alliance. Model Hypothesis 3a shows that complementarities can exist not only between firm and alliance level interactions (Rothaermel and Hess, 2007), but also between alliances themselves.

With respect to this study's absorptive link hypotheses, models Hypothesis 3 - Hypothesis 4 indicate a firm's cumulative and diverse knowledge experiences positively influence a firm's product performance. This suggests that a Penrosian (1959) explanation of the product discovery process can be used to further supplement absorptive capacity explanations of innovation. In particular, as the concept of absorptive capacity rests on a firm's 'prior knowledge' (Cohen and Levinthal, 1990), a firm's prior knowledge may entail more than its memory but may also entail a firm's cumulative and diverse knowledge of resources uses. Furthermore and as indicated in model Hypothesis 3a, a firm's cumulative knowledge in discovering new resources uses from its alliances partners is subject to diminishing return effects and thus, unlike a firm's memory, this prior knowledge implies a need to manage alliances more effectively. However, with regards to the moderating effects on a firm's diverse knowledge, model Hypothesis 4a did not support our absorptive link arguments. Yet, since diverse knowledge increases a firm's ability to relate to a broader set of external experiences (Cohen and Levinthal, 1990), we examined this relationship by introducing a model Hypothesis 4a (optional) that included the interaction between a firm's diversity and the aggregation of 'all' alliance types. In this model, the positive yet diminishing effects described in Hypothesis $4 \mathrm{a}$ was observed. This is also consistent with McFadyen and Cannellas' (2004) findings. This finding thereby suggests the behaviour of a firm's absorptive link is sensitive to the level of aggregation used in the construction of alliances. With regards to the commercial aspects of the absorptive link concept, model Hypothesis 5 indicated that a firm's product in development did not influence product performance (Hypothesis 5) and that the diminishing effects of a firm's commercializing alliances on a firm's product development was not observed (Hypothesis 5a). This suggests that although prior studies indicated that strategic alliances can be subject to opportunistic threats of adverse selection, moral hazard and hold up (Jones et al., 1997; Osborn and Hagedoorn, 1997: Pisano, 1990), this lack of a diminishing effect suggests that such threats of opportunism among commercializing alliances are not a significant deterrent to a firm's absorptive link. Model Hypothesis 6. provides support for Hypotheses 6 and 6a which suggest that a firm's product performance is not only driven by its commercial knowledge (i.e. M\&A experience), but that such commercial knowledge is instrumental to exploiting the 'pecking order' dynamics of R\&D alliances. This is consistent with Liebeskind et al. (1996) who argue that there tends to be a winner takes all or technology race dynamic in the biotechnology industry. Lastly, since a firm's product performance depends on both a firm's functional as well as commercial knowledge of resource uses, the joint impact of these two distinct sources of 'prior' knowledge appears to be supported in model Hypothesis 6. In this model, all four proxies of prior knowledge - Cumulative, Diverse, Products in Development, and M\&A - were positive and significant $(P<1 \%$ level). This suggests that future research on the absorptive capacity concept may want to consider these different forms of 'prior knowledge'.

\section{Conclusions}

This study posed the question: what determines a biotechnology firm's product success, if the product requires multiple technologies that are not held by any one firm? To address this question, this study introduced and empirically examined an 'absorptive link' concept to the biotechnology product market. A central argument of this study is that: driven by a firm's functional and commercialized knowledge, a firm's absorptive link serves 
to not only discover and commercialize a firm's varied resources uses, but also that of its alliance partners. Such a concept generated 6 testable hypotheses and was empirically examined in a sample of 372 biotechnology firms. Based on this concept of absorptive link and its analyses, this study offers three key contributions and implications to product performance research.

First, as cross level analyses are increasingly called for in management research (Rynes, 2005), the concept of absorptive link explains a firm's product performance by bridging firm level factors with that of alliance level considerations. Such a concept builds upon recent studies that advocate a more multi-levelled approach to innovation research (Rothaermel and Deeds, 2006; Rothaermel and Hess, 2007; Hess and Rothaermel, 2011). A contribution of this absorptive link concept is that a firm's memory is but one of many experiences that promote the assimilation of external experiences (Cohen and Levinthal, 1990). In addition to a firm's memory, a firm's functional and commercial knowledge of resources uses is argued to also impact this assimilation of alliance experiences by seeking to discover and commercialize new resources uses that extend beyond a firm's organizational boundaries. Such knowledge experiences, as a consequence, are distinct from other types of alliance experiences. For instance, alliance management capability research (Ireland et al. 2002; Rothaermel and Deeds, 2006) contends that repeated alliance exchanges or alliance experiences promote the transfer of complex, tacit, and causally ambiguous knowledge. This transfer of knowledge can overcome various transaction cost problems relating to hold up moral hazard in learning races, and an underinvestment in assets by alliance partnerships etc (Ireland et al., 2002). Thus, alliance management capability has been argued to improve a firm's performance - including that of its product performance - because a firm's experiences in managing such alliances can curtail such governance problems (see also Dyer and Singh, 1998; Ireland et al., 2002; Rothaermel and Deeds, 2006). Although such governance provides a more equitable distribution of rents amongst alliance partners (see Dyer and Singh, 1998; Ireland et al., 2002; Osborn and Hagedoorn, 1997), such an approach, however, does not explain the types of knowledge responsible for the discovery of these rents. A firm's absorptive link, driven by its functional and commercial knowledge of resource uses, addresses this gap in which product innovation not only depends on a firm's alliance experiences in governing 'effective' partnerships, but it also depends on a firm's ability to discover and commercialize new uses of resources that are not known by their alliance partners.

Second, the functional and commercialized aspects of the absorptive link concept also extend Penrosian explanations of the product discovery process. With regards to a firm's functional knowledge of resource uses, the concept of absorptive link extends Penrose's (1959) firm level analysis to a network level of examination. This study argues that a firm's cumulative and diverse knowledge of the functional uses of resources enable the firm to 'see an eventual combination of resources' that extend beyond a firm's organizational boundaries to include those resource combinations and uses of its alliance partners. This enables the firm to solve a 'larger jigsaw problems' that was not previously envisioned by Penrose's treatment on the theory of the growth of firm (see also Denrell et al., 2003; $\mathrm{Ng}$, 2007). Furthermore, the 'commercial' aspects of the absorptive link concept also extend Transaction Costs explanations of product diversification (Denrell et al., 2003; Williamson, 1975). Williamson (1975) and Denrell et al. (2003) argue that a firm diversifies into new and unrelated product markets because it has an internal capital market that is better suited to discovering the commercial value of a new product initiative than that of the market price system. The distinction with this study is that the commercial value of a new product does not depend on an internal competitive valuation process (e.g. Williamson, 1975), but rather can depend on a firm's commercialized knowledge. Specifically, unlike Williamson (1975), a firm introduces new products to the market not because of an internal competitive market process, but because the firm has commercial knowledge about the functional uses of resources that cannot be readily known by the external market.

Third, this concept of absorptive link also introduces two implications to the practicing manager. First, and especially in accordance to absorptive capacity research, a firm's investment in $R \& D$ is often viewed as an important means to developing new products because it enables a firm to assimilate external technologies (Rothaermel and Hess, 2007). However, when dealing with the biotechnology industry, managers may at times face many research projects that compete for internal corporate resources and thus investments in $R \& D$ offers limited guidance on those projects a manager should invest in. This study argues that along with standard capital budgeting techniques, the selection of internal research projects by managers should consider projects that the manager has the most functional and commercial knowledge about. That is to say, managers should not just focus their investments in basic research, as basic research inherently has many functional uses, but rather the selection of these internal projects needs to also consider those projects in which a firm has commercial experiences in bring them to market. Such an attention to a firm's functional and commercial experiences are not typically addressed in capital budgeting techniques, such as Net Present Value analysis, and that of Real option 
valuations. The attention to these knowledge considerations in conjunction with these valuation techniques can thus assist in a manager's selection of internal investment projects. Second and subsequently, as such functional and commercial knowledge can be leveraged to the resources of alliance partners, the implication to managers of new products is that investments in $R \& D$ is not a panacea to the success of its firm's product, but success requires considering that the functional and commercialized aspects of its investment operates within a greater firm-inter-firm context. More generally speaking, the broader implication to mangers of the absorptive link concept is it serves to broaden a firm's product discovery process to outside experiences and thus mitigates 'myopic' behaviours that can inhibit a firm's product innovation process. That is, as managers tend to resist the adoption of external ideas, the concept of absorptive link serves to mitigate problems relating to 'not invented here syndrome'.

In light of these distinctions, this study's absorptive link arguments and findings should however be tempered by its limitations. First, the development of new products involves a temporal component and thus future research should consider using panel regression methods (e.g. Hess and Rothaermel, 2011; Rothaermel and Hess, 2007). Second, our measures of a firm's prior knowledge are relatively course grained, especially with that of a firm's age. Therefore, other measures should be examined to determine the robustness of our absorptive link arguments. Nevertheless, this study's findings do provide some initial promise with the proposed absorptive link construct and thus future empirical research is called for to further validate the robustness of this concept.

\section{References}

Aiken, L.S. and S.G. West, 1991. Multiple regressions: testing and interpreting interactions. Sage Publications, NewBury Park, CA, USA.

Barney, J., 1986. Strategic factor markets: Expectations, luck and business strategy. Management Science, 32:1231-1241.

Baum, J.A.C., T., Calabrese and B.S. Silverman, 2000. Don't go it alone: alliance network composition and startup' performance in Canadian biotechnology. Strategic Management Journal, 21(3): 267-294.

Bettis, R. and M. Hitt, 1995. Technological transformation and the new competitive landscape. Strategic Management Journal, 16: 7-19.

Capron, L., 1999. The long-term performance of horizontal acquisitions. Strategic Management Journal, 20(11): 987-1018.

Chan, S.H., J.W. Kesinger, A.J. Keown and J.D. Martin, 1997. Do strategic alliances create value? Journal of Financial Economics, 46: 199-221.
Christensen, C.M. and J.L. Bower, 1996. Customer power, strategic investment, and the failure of leading firms. Strategic Management Journal, 17(3): 197-218.

Cohen, W.M. and D.A. Levinthal, 1990. Absorptive capacity: a new perspective on learning and innovation. Administrative Sciences Quarterly, 35: 128-152.

Coleman, J.S., 1988. Social in the creation of human capital. American Journal of Sociology, 84: 95-120.

Danneels, E., 2002. The dynamics of product innovation and firm competences. Strategic Management Journal, 23: 1095-1121.

Danneels, E., 2003. Tight-loose coupling with customers: the enactment of customer orientation. Strategic Management Journal, 24: 559-576.

Danzon, P.M., A. Epstein and S. Nicholson, 2003. Mergers and acquisitions in the pharmaceutical and biotech industries. University of Pennsylvania: Wharton School. Available at: http:// www.simon.rochester.edu/fac/vanhorn/Conferencepapers/ merger_Sept03.pdf.

Deeds, D.L. and C. Hill, 1996. Strategic alliances and the rate of new product development: an empirical study of entrepreneurial biotechnology firms. Journal of Business Venturing, 11: 41-55.

Denrell, J., C. Fang and S. Winter, 2003. The economics of strategic opportunity. Strategic Management Journal, 24: 977-990.

Dutta, S., O. Narasimhan and S. Rajiv, 1999. Success in hightechnology markets: is marketing capability critical? Marketing Science, 18(4): 547-568.

Dyer, J. and H. Singh, 1998. The relational view: cooperative strategy and sources of inter-organizational competitive advantage. Academy of Management Review, 23(4): 660-679.

Forbes, 2005. Bristol Meyers cannot be trusted. Available at: http://www.forbes.com/associatedpress/feeds/ap/2005/06/14/ ap2093061.html.

Gargiulo, M. and M. Benassi, 2000. Trapped in your own net? network cohesion, structural holes, and the adaptation of social capital. Organization Science, 11(2): 183-196.

Graves, S.B. and N.S. Langowitz, 1993. Innovative productivity and returns to scale in the pharmaceutical industry. Strategic Management Journal, 14: 593-605.

Greene, W.H., 2000. Econometric analysis: 4th edition. Prentice Hall, Upper Saddle River, New Jersey.

Gujarati, D., 1988. Basic econometrics: 2nd edition. McGraw-Hill, New York, NY, USA.

Hamel, G. and C.K. Prahalad, 1991. Corporate imagination and expeditionary marketing. Harvard Business Review, 69(4): 81-92.

Harrison, J.S., M.A. Hitt, R.E. Hoskisson and R.D. Ireland, 2001. Resource complementarity in business combinations: extending the logic to organizational alliances. Journal of Management, 27: 679-690.

Helfat, C.E. and M.A. Peteraf, 2003. The dynamic resource-based view: capabilities lifecycles. Strategic Management Journal, 24: 997-1010. 
Helfat, C.E. and R.S. Raubitschek, 2001. Product sequencing: coevolution of knowledge, capabilities, and products. Strategic Management Journal, 21: 961-980.

Hess, A.M. and F.T. Rothaermel, 2011. When are assets complementary? star scientists, strategic alliances and innovation in the pharmaceutical industry. Strategic Management Journal, in press. DOI: 10.1002/smj.916

Hoang, H. and F.T. Rothaermel, 2005. The effect of general and partner specific alliance experiences on joint R\&D project performance. Academy of Management Journal, 48: 332-345.

Ireland, R.D., M.A. Hitt and D. Vaidyanath, 2002. Alliance management as a source of competitive advantage. Journal of Management, 28: 413-446.

Jansen, J.P., F.A.J. Van Den Bosch and H.W. Volberda, 2005. Managing potential and realized absorptive capacity: how do organizational antecedents matter? Academy of Management Journal, 48: 999-1015.

Jones, C., W.S. Hesterly and S.P. Borgatti, 1997. A general theory of network governance: exchange conditions and social mechanisms. Academy of Management Review, 22: 911-945.

Lane, P.J. and M. Lubatkin, 1998. Relative absorptive capacity and interorganizational learning. Strategic Management Journal, 19: 461-477.

Levinthal, D.A. and J.G. March, 1993. The myopia of learning. Strategic Management Journal, 14: 95-112.

Lichtenthaler, U. and E. Lichtenthaler, 2010. Technology transfer across organizational boundaries: absorptive capacity and desorptive capacity. California Management Review, 53: 154-170.

Lichtenthaler, U., 2009. Absorptive capacity, environmental turbulence, and the complementarity of organizational learning process. Academy of Management Journal, 52: 822-846.

Liebeskind, J.P., A. Oliver, L. Zucker and M. Brewer, 1996. Social networks, learning, and flexibility: sourcing scientific knowledge in new biotechnology firms. Organization Science, 7: 428-443.

McEvily, S.K. and B. Chakravarthy, 2002. The persistence of knowledge-based advantage: an empirical test for product performance and technological knowledge. Strategic Management Journal, 23: 285-305.

McFadyen, M.A and A.A. Cannella, 2004. Social capital and knowledge creation: diminishing returns of the number and strength of exchange relationships. Academy of Management Journal, 47: 735-747.

Montoya-Weiss, M. and R. Calantone, 1994. Determinants of new product performance: a review and meta analysis. Journal of Product Innovation Management, 11: 397-417.

Mowery, D., J. Oxley and B. Silverman, 1996. Strategic alliances and inter-firm knowledge transfer. Strategic Management Journal, 17: 77-91

Nelson, A. and S.G. Winter, 1982. An evolutionary theory of economic change. Harvard University Press, Boston, MA, USA.
Nerkar, A. and P.W. Roberts, 2004. Technological and productmarket experience and the success of new product introductions in the pharmaceutical industry. Strategic Management Journal, 25: 779-799.

$\mathrm{Ng}$, D. 2004. The social dynamics of diverse and closed networks. Human Systems Management, 23: 111-122.

$\mathrm{Ng}$, D., 2007. A modern resource based approach to unrelated diversification. Journal of Management Studies, 44: 1481-1502.

Ng, D., J. Unterschultz and E. Laate, 2006. The performance of relational ties: a functional approach in the biotechnology industry. Journal on Chain and Network Science, 6: 9-21.

Nicholls-Nixon, C. and C.Y. Woo. 2003. Technology sourcing and output of established firms in a regime of technological change. Strategic Management Journal, 24: 651-666.

Osborn, R.N. and J. Hagedoorn, 1997. The institutionalization and evolutionary dynamics of interorganizational alliances and networks. Academy of Management Journal, 40: 261-278.

Pennings, J.M. and F. Harianto, 1992. Technological networking and innovation implementation. Organization Science, 3: 356-382.

Penrose, E., 1959. The theory of the growth of the firm. Oxford University Press, New York, NY, USA.

Peteraf, M.A. and M.E. Bergen, 2003. Scanning dynamic competitive landscapes: a market-based and resource-based framework. Strategic Management Journal, 24: 1027-1041.

Pisano, G., 1990. The R\&D boundaries of the firm: an empirical analysis. Administrative Science Quarterly, 35: 153-176.

Powell, W.W., K.W. Koput and L. Smith-Doerr, 1996. Interorganizational collaboration and the locus of innovation: networks of learning in biotechnology. Administrative Science Quarterly, 41: 116-145.

Rothaermel, F, 2001. Complementary assets, strategic alliances, and the incumbent's advantage: an empirical study of industry and firm effects in the biopharmaceutical industry. Research Policy, 30: 1235-1251.

Rothaermel, F.T. and A.M. Hess, 2007. Building dynamic capabilities: innovation driven by individual-, firm-, and network-level effects. Organization Science, 18: 898-921.

Rothaermel, F.T. and D.L. Deeds, 2004. Exploration and exploitation alliances in biotechnology: a system of new product development. Strategic Management Journal, 25: 201-221.

Rothaermel, F.T. and D.L. Deeds, 2006. Alliance type, alliance experience and alliance management capability in high technology ventures. Journal of Business Venturing, 21: 429-460.

Rothaermel, F.T. and M.T. Alexandre, 2009. Ambidexterity in technology sourcing: the moderating role of absorptive capacity. Organization Science, 20: 759-780

Rynes, S.L., 2005. From the editors: Taking stock and looking ahead. Academy of Management Journal, 48: 9-15.

Schoonhoven, C.B., K.M. Eisenhardt and K. Lymman, 1990. Speeding products to market: waiting time to first product introduction in new firms. Administrative Science Quarterly, 35: 177-207. 
Schumpeter, J. A., 1934. The Theory of economic development (R. Opic, Trans.). Harvard University Press. (original work published in 1912), Cambridge, MA, USA.

Shan, W., G. Walker and B. Kogut, 1994. Interfirm cooperation and startup innovation in the biotechnology industry. Strategic Management Journal, 15: 387-394.

Teece, D.J., 1982. Towards an economic theory of the multiproduct firm. Journal of Economic Behavior and Organization, 3: 39-63.

Teece, D.J., 2000. Managing intellectual capital: organizational, strategic, and policy dimensions. Oxford University Press, New York, NY, USA.

Todorova, G. and B. Durisin, 2007. Absorptive capacity: valuing a reconceptualization. Academy of Management Review, 32: 774-786.

Van den Bosch, F.A.J., H.W. Volberda and M. De Boer. 1999. Coevolution of firm absorptive capacity and knowledge environment: organizational forms and combinative capabilities. Organization Science, 10: 551-568.

Walter, G.A. and J.B. Barney, 1990. Management objectives in mergers and acquisitions. Strategic Management Journal, 11: 79-86.

Wernerfelt, B., 1984. A resource-based view of the firm. Strategy Management Journal, 5: 171-180.

Williamson, O.E. 1975. Markets and hierarchies, analysis and anti-trust implications: a study in the economics of internal organization. Free Press, New York, NY, USA.

Wooldridge, J.M., 2003. Introductory econometrics: a modern approach 2nd edition. South Western College Publishing, Cincinatty, $\mathrm{OH}$, USA.

Zahra, S.A. and G. George, 2002. Absorptive capacity: a review, reconceptualization, and extension. Academy of Management Review, 27:185-203.

Zhao, Z.J. and J. Anand, 2009. A multi-level perspective on knowledge transfer: evidence from the Chinese automotive industry. Strategic Management Journal, 30: 959-983. 
